\title{
The Portfolio Choices of Hispanic Couples*
}

\author{
Deborah A. Cobb-Clark, Australian National University \\ Vincent A. Hildebrand, York University
}

Objectives. The objective of this article is to assess the overall wealth level and portfolio choices of Hispanic families. Methods. We use Survey of Income and Program Participation (SIPP) data to first estimate the determinants of net worth. Conditioning on overall wealth levels, we then estimate a model of asset portfolios. Results. Our results reveal that Hispanic couples as a group are less wealthy than otherwise similar white couples, although there is substantial variation across Hispanic-origin groups. Accounting for these wealth disparities, Hispanic couples hold less financial wealth, but more real estate and business equity than do white couples. Conclusions. Much of the disparity in portfolio choices of Hispanics as a group relative to whites appears to stem from the fact that they are less wealthy. At the same time, it is important to separately analyze the wealth position of distinct Hispanic-origin groups.

Wealth is an important measure of overall economic well-being. In particular, wealth accumulation provides the means for families to not only finance their current consumption, but to also maintain their living standards in retirement or in periods of economic hardship. Wealth in the form of housing provides direct services (Wolff, 1998), while the neighborhoods in which wealthier families live are characterized by better schools, better health facilities, and less crime (Gittleman and Wolff, 2000; Altonji and Doraszelski, 2005). Finally, there is a positive relationship between political influence and wealth (Osili and Paulson, 2005).

Though there is still much we do not understand about how families accumulate wealth, it is clear that-whatever the process- the result is substantial disparities in wealth. The wealthiest 10 percent of the U.S. population are estimated to hold more than 70 percent of total wealth despite receiving closer to 40 percent of total income (Wolff, 2000). Moreover, there is both a racial and ethnic dimension to the distribution of wealth.

*Direct correspondence to Vincent Hildebrand, Department of Economics, 363 York Hall, Glendon College, York University, Toronto, Ontario, M4N 3M6 Canada 〈vincent@ econ.yorku.ca〉. The authors will share all data and coding information with those wishing to replicate the study and thank two anonymous referees for useful comments on previous drafts of this article. Vincent Hildebrand gratefully acknowledges support from the Social and Economic Dimensions of an Aging Population (SEDAP) Research Program at McMaster University. 
White households are simply much wealthier than their black or Hispanic counterparts. ${ }^{1}$ Specifically, Hispanic households are estimated to have less than 10 cents for every dollar of wealth owned by white households, while many black and Hispanic families are especially vulnerable to economic downturns as more than one in four of them have zero or negative net worth (Kochhar, 2004). ${ }^{2}$

Though the causes and consequences of the racial wealth gap have been a matter of extensive debate (see, e.g., Blau and Graham, 1990; Gittleman and Wolff, 2000; Menchik and Jianakoplos, 1997; Chiteji and Stafford, 1999; Hurst, Ming, and Stafford, 1998), less is known about the factors driving the wealth position of Hispanics. ${ }^{3}$ We intend to contribute to filling this gap in the literature by analyzing the net worth and portfolio allocations of couple-headed, Hispanic families using Survey of Income and Program Participation (SIPP) data. These data are unique in allowing us to separately consider the wealth position of different Hispanic groups. Hispanics are often treated as a single, homogenous group; however, there are clear regionof-origin and nativity differences in earnings and expenditure patterns that are not driven solely by the demographic composition of various groups (Paulin, 2003). Given the close link between income and expenditure on the one hand and saving on the other, it is sensible to expect the wealth position of the Hispanic population to also vary across different groups. Consequently, we explicitly consider detailed Hispanic-origin groups that are defined by both nativity status and geographic origin. As such, this article builds on our previous work, which documents the wealth position of the U.S. foreign-born population generally and analyzes the source of the aggregate wealth gap for Mexican Americans (Cobb-Clark and Hildebrand, 2006a, 2006b), by providing a detailed analysis of the wealth positionincluding asset portfolios - of six separate groups of Hispanics.

Our focus on understanding the portfolio choices of Hispanic couples is particularly important for several reasons. First, portfolio choices-in particular the decision to hold or not to hold specific assets- have important implications for the rate at which wealth is accumulated and thus for related issues such as the adequacy of precautionary savings and retirement income (Bertaut and Starr-McCluer, 1999). Second, asset portfolios are directly linked to the relative wealth position of different groups. Choudhury (2001), for example, concludes that overall differences in wealth among racial and ethnic groups are generated primarily by the financial assets those groups own. Hurst, Ming, and Stafford (1998) reach a similar conclusion. Third, assets differ in terms of their expected rates of return, riskiness, and

\footnotetext{
1"White" and "black" refer to the non-Hispanic portions of those populations.

${ }^{2}$ Moreover, Kochhar (2004) concludes that the relative wealth position of blacks and Hispanics declined following the 2001 recession. See also Hao (2003), Wakita, Fitzsimmons, and Liao (2000), Wolff (2000), Choudhury (2001), Cobb-Clark and Hildebrand (2006b), and Smith (1995) for estimates of the wealth gap faced by Hispanics.

${ }^{3}$ Recent exceptions are Kochhar (2004) and Cobb-Clark and Hildebrand (2006b).
} 
liquidity, leading them to serve different functions in providing for the household's financial security. Finally, portfolio decisions play a key role in determining how changes in macro-economic conditions-interest rates, stock prices, inflation, and unemployment-affect household spending and saving (Bertaut and Starr-McCluer, 1999).

Seen in this light, there are reasons to be concerned about the portfolios of Hispanic families. Owner-occupied housing is a particularly important asset as it accounts for approximately one-third of households' total net worth (Wolff, 1998). In addition to providing direct benefits to families, high homeownership rates enhance neighborhoods' social networks (Haurin, Dietz, and Weinberg, 2002). Although housing equity is generally more equally distributed than nonhousing equity, it remains the case that Hispanic families are less likely to own their own homes - and have less equity when they do-than their white counterparts (Choudhury, 2001; Kochhar, 2004; Smith, 1995). Hispanics are also much less likely to own financial assets, particularly riskier assets (Choudhury, 2001; Wolff, 1998, 2000). This is problematic because asset income plays an important role in generating retirement income. Consequently, among minority families, there are virtually no savings that seem directed at future income security during old age (Smith, 1995). ${ }^{4}$

What drives these ethnic differences in portfolio allocations is not at all clear. Chiteji and Stafford (1999), for example, postulate that portfolio choices are influenced by a social-learning process in which parents' decisions to hold certain assets influence the subsequent portfolio choices of their children. Though the issue is still open to debate, there is empirical evidence for a cultural basis to savings behavior. Osili and Paulson (2005), for example, conclude that immigrants who come from countries with effective institutions for protecting individual property rights are more likely to participate in the U.S. financial market. Smith (1995) suggests that black and Hispanic households are more likely to have very short time horizons and less likely to believe that leaving a bequest is important-both of which would have important implications for wealth accumulation over the lifecycle. Others have drawn a link between high immigration rates and low net worth among Hispanics, suggesting that disparities in earnings potential in conjunction with differential incentives to save and consume out of current income imply that the portfolio choices of immigrants are likely to differ from those of the native born (Amuedo-Dorantes and Pozo, 2002; Osili and Paulson, 2004; Cobb-Clark and Hildebrand, 2006a). Moreover, institutional barriers associated with ethnicity, nativity, legal status, and language skills may constrain Hispanics' access to the financial markets that facilitate the purchase of assets such as housing, stocks, and bonds (Osili and Paulson, 2004). Finally, Hispanics as a group are younger, less likely to be married,

\footnotetext{
${ }^{4}$ More specifically, Smith (1995) calculates that whites have a 10-fold advantage in stocks and a 30 -fold advantage in bonds.
} 
and have more children than other groups (U.S. Bureau of the Census, 1995, 2001a, 2001b). These demographic differences — which are directly related to stage of the lifecycle-are also influential in the portfolio choices of Hispanics.

We begin by measuring the factors driving the overall net worth of Hispanic couples. This step of the analysis is critical in providing the backdrop against which we can evaluate portfolio choices. We then move on to assess the ways-conditional on their level of net worth-Hispanic couples allocate their wealth across major asset types. To this end, we estimate the effect of income, demographic characteristics, and geographic origin on the portfolio choices of Hispanic families using a multivariate, reduced-form model of asset composition. This allows us to directly estimate the way different Hispanic groups would choose to allocate an additional dollar of wealth across their holdings in real estate, financial assets, vehicles, and businesses.

Our results reveal that Hispanic couples have on average approximately $\$ 70,000$ less net worth than otherwise similar white couples, although there is substantial variation across Hispanic-origin groups. Mexican-American couples have significantly more wealth-while Puerto Rican and foreignborn other Hispanic couples have significantly less wealth-than Hispanics as a whole. Much of the disparity in the portfolio choices of Hispanics relative to whites appears to stem from the fact that Hispanics are less wealthy. Accounting for differential wealth levels, Hispanic couples as a group hold relatively less financial wealth, but more real estate and business equity than do white couples.

The second section of this article reviews the details of the SIPP data, while the wealth position of Hispanic couples is discussed in the third. We then present both our empirical specification and the estimation results. We end by discussing our conclusions and suggested directions for future research.

\section{The Survey of Income and Program Participation}

This article exploits data drawn from the 1984, 1985, 1987, 1990, 1991, 1992, 1993, 1996, and 2001 surveys of the Survey of Income and Program Participation (SIPP). ${ }^{5}$ Each SIPP survey captures between approximately 14,000 to 36,700 households, which are interviewed once every four months over a two-and-one-half- to four-year period. As low-income households were oversampled in some years, we use sample weights throughout the analysis. ${ }^{6}$ Pooling data from all the panels in which both wealth and immigration information is collected allows us to construct a data set in which detailed Hispanic-origin groups can be considered.

\footnotetext{
${ }^{5}$ See Cobb-Clark and Hildebrand (2006a) for a discussion of alternative data sources for studying the wealth levels of foreign-born individuals.

${ }^{6}$ See the SIPP webpage (http://www.sipp.sensus.gov/sipp/).
} 
Our wealth data are derived from the topical module on household assets and liabilities, which is usually administered in detail once in each SIPP panel. $^{7}$ Using these detailed data on assets and liabilities, we construct a family's equity in four major asset categories: ${ }^{8}$ (1) financial wealth (all interest-bearing assets held in banking and other institutions, stocks, mutual funds, IRAs, and KEOGH accounts); (2) businesses; (3) real estate (family home and other real estate); and (4) vehicles (including cars, boats, motor homes, etc.). Total net worth is the sum of equity across all asset categories. Although providing detailed information about a wide range of assets and liabilities, the SIPP wealth module does not canvas any future pension rights such as equity in private pension plans or Social Security wealth. Moreover, SIPP does not ask directly about assets held offshore, which may be particularly important for foreign-born Hispanic households. Although respondents are not explicitly told to exclude any off-shore assets when reporting their asset holdings, it is likely that off-shore assets are disproportionately underreported and it may be most useful to think of SIPP data as capturing U.S.-based wealth only.

Our estimation sample includes couple-headed, Hispanic and non-Hispanic white households in which the reference person is between 25 years and 75 years old. Although single-headed households are also of interest, the wealth patterns of these families are sufficiently different as to warrant separate treatment (Cobb-Clark and Hildebrand, 2006a). Given our interest in the wealth gap faced by Hispanics, we have retained all couples in which both partners are native-born, non-Hispanic whites. ${ }^{9}$ Moreover, we have retained all couples in which both partners report being Hispanic irrespective of nativity status. We then define six possible Hispanic-origin groups based on the nativity status and region of origin of the reference person. Couples are classified as either: (1) native-born Mexican American (reference person identifies as being Mexican American, Chicano, or of Mexican origin (or descent)); (2) Puerto Rican; (3) native-born other Hispanic; (4) foreignborn Cuban American (reference person was born in Cuba); ${ }^{10}$ (5) foreignborn Mexican American (reference person was born in Mexico); or (6) foreign-born other Hispanic (reference person was born in Central/South America or in the Caribbean). The resulting sample of 64,343 households includes 59,299 non-Hispanic whites, 1,490 native-born Mexican Americans, 402 Puerto Ricans, 254 native-born other Hispanics, 277 foreign-

\footnotetext{
${ }^{7}$ The exceptions are 1984, 1985, 1996, and 2001.

${ }^{8}$ Equity reflects the value of the asset net of any liability. Liabilities measured in SIPP include both debts secured by assets and unsecured debts (including liabilities such as credit card or store bills, bank loans, and other unsecured debts).

${ }^{9}$ We dropped 3,036 couples with non-Hispanic heads and either native-born Hispanic or foreign-born spouses as well as 786 couples with Hispanic heads and non-Hispanic spouses. Preliminary analysis suggests that these couples have wealth holdings that are similar to nonHispanic white couples.

${ }^{10}$ Unfortunately, the sample of native-born Cubans $(N=42)$ is too small for analysis.
} 
born Cuban Americans, 1,798 foreign-born Mexican Americans, and 823 foreign-born other Hispanics. ${ }^{11}$ Descriptive statistics by Hispanic-origin group are reported in the Appendix.

\section{The Wealth Position of Hispanic Couples}

A detailed description of the relative wealth position of Hispanic couples is provided in Table $1 .^{12}$ The mean net worth of Hispanic couples is $\$ 48,355$, while white couples are on average approximately three times wealthier. ${ }^{13}$ As expected, there is substantial disparity in wealth position across nativity status and region of origin within the wider Hispanic population. In particular, Hispanics from Cuba or Central and South America have higher net worth than couples from Mexico or Puerto Rico. Moreover, the differences in the mean and median wealth levels reported in Table 1 indicate that wealth is highly skewed. Although Puerto Rican couples have on average $\$ 41,562$ in U.S.-based net worth, for example, a Puerto Rican couple at the midpoint of the wealth distribution has just over $\$ 6,000$. These differentials are highlighted by the plots of the empirical cumulative net worth distribution for whites and Hispanics reported in Figure 1. This figure also reveals that the vast majority (more than 90 percent) of white households have positive net worth and that the wealth gap between whites and Hispanics widens as one moves up the wealth distribution.

Disparities are also evident when we consider couples' equity in different types of assets. Although Hispanic couples as a group have between onethird and one-half the wealth in real estate, businesses, and vehicles of whites, their financial assets amount to just over one-ninth the amount held by their white counterparts. ${ }^{14}$ Ownership of financial assets is highest for foreign-born Cuban Americans and native-born other Hispanics, but is particularly low among Puerto Ricans and foreign-born Mexican Americans. Fully, 96.9 percent of white couples have some financial assets in the United States (such as bank accounts, stocks, bonds, etc.), though this is true of only 72.6 and 81.4 percent of foreign-born Mexican-American and Puerto Rican

\footnotetext{
${ }^{11}$ The sample thus contains a number of "mixed" Hispanic couples in which although both partners are Hispanic, either nativity status or geographic origin differs between the two partners. In this case, couples have been assigned to a Hispanic-origin group on the basis of the characteristics of the reference person. Later, we discuss the sensitivity of our results to the inclusion of these mixed couples.

${ }^{12}$ Specifically, Table 1 gives weighted mean and median asset holdings in 1992 constant dollars for the couples in our sample. Sampling weights are used to take into account the stratified sampling design.

${ }^{13}$ The relative wealth position of Hispanic couples discussed here is substantially better than that of Hispanic households as a whole (see, e.g., Kochhar, 2004). This occurs because the relative wealth gap faced by Hispanic single-headed households is very large. Consequently, it is useful to disaggregate by household type.

${ }^{14}$ Amuedo-Dorantes and Pozo (2002) discuss the asset portfolios of young immigrant and native-born households.
} 
TABLE 1

The Wealth Position of Non-Hispanic White and Hispanic Couple-Headed

\begin{tabular}{|c|c|c|c|c|c|c|c|c|}
\hline & $\begin{array}{l}\text { NHWs } \\
\text { Natives }\end{array}$ & $\begin{array}{c}\text { All } \\
\text { Hispanics }\end{array}$ & NBMAs & $\mathrm{NBOHs}$ & $\begin{array}{c}\text { Puerto } \\
\text { Rico }\end{array}$ & FBCUs & FBMAs & $\mathrm{FBOHs}$ \\
\hline $\begin{array}{l}\text { Mean net } \\
\text { wealth }\end{array}$ & 139,284 & 48,355 & 55,735 & 77,424 & 41,562 & 84,412 & 32,789 & 50,677 \\
\hline $\begin{array}{l}\text { Median net } \\
\text { wealth }\end{array}$ & 77,942 & 13,813 & 24,958 & 30,931 & 6,020 & 31,829 & 7,375 & 8,933 \\
\hline \multicolumn{9}{|l|}{$\begin{array}{c}\text { Mean Asset } \\
\text { Levels }\end{array}$} \\
\hline $\begin{array}{l}\text { Financial } \\
\text { wealth }\end{array}$ & 43,003 & 4,855 & 5,029 & 10,974 & 5,734 & 14,908 & 1,120 & 6,924 \\
\hline Busir & & & & & & & & 4,936 \\
\hline & 370 & 35,9 & & 56,633 & 30,554 & 56,626 & 26,400 & 34,464 \\
\hline Vehicles & 695 & 4,184 & 4,837 & 4,815 & 3,099 & 5,998 & 3,424 & 4,353 \\
\hline $\begin{array}{c}\text { Proportion } \\
\text { Owning }\end{array}$ & & & & & & & & \\
\hline $\begin{array}{c}\text { Financial } \\
\text { wealth }\end{array}$ & 0.969 & 0.81 & 0.870 & 0.914 & 0.814 & 0.917 & .726 & 0.866 \\
\hline Business & & 0.077 & & 0.094 & 0.043 & 0.166 & 0.055 & 0.109 \\
\hline & & & & & & 0.7 & & 0.457 \\
\hline Vehicle & 0.974 & 0.891 & 0.942 & 0.870 & 0.744 & 0.931 & 0.906 & 0.828 \\
\hline $\begin{array}{l}\text { Current } \\
\text { income }^{a}\end{array}$ & 15,843 & 9,743 & 10,684 & 13,595 & 10,895 & 11,323 & 7,412 & 10,725 \\
\hline$N^{\prime \prime}$ & 59,299 & 5,044 & 1,490 & 254 & 402 & 277 & 1,798 & 823 \\
\hline
\end{tabular}

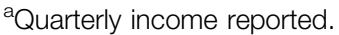

Note: Own calculation based on SIPP 1984, 1985, 1987, 1990, 1991, 1992, 1993, 1996, and 2001 panels. Weighted sample means reported unless otherwise indicated. Reported sample means calculated from all households regardless of asset ownership. NHWs = Non-Hispanic whites, NBMAs = Native-born Mexican Americans, NBOHs = Native-born other Hispanics, FBCUS $=$ Foreign-born Cubans, FBMAs $=$ Foreign-born Mexican Americans, $\mathrm{FBOH}=$ Foreign-born other Hispanics. All figures deflated using Monthly CPI-U BLS, Base = June 1992.

couples, respectively. Perhaps not surprisingly, ownership of real estate is closely related to nativity status. Native-born Hispanics have real estate ownership rates that - while lagging behind those of whites-are substantially higher than those of foreign-born Hispanics and Puerto Ricans. The exception is foreign-born Cuban Americans, who have a propensity to own real estate that is slightly higher than that of native-born Hispanic groups.

Finally, relative income gaps are much smaller than relative wealth gaps. As a group, Hispanics face an income gap of approximately 40 percent, while the gap in wealth is on the order of 65 percent. ${ }^{15}$ The fact that the wealth gap is substantially larger than the income gap is not surprising given that a household's wealth stock reflects—among other things—the

\footnotetext{
${ }^{15}$ These income differentials are consistent with Grogger and Trejo (2002).
} 
FIGURE 1

Cumulative Distribution of Net Worth by Hispanic Group

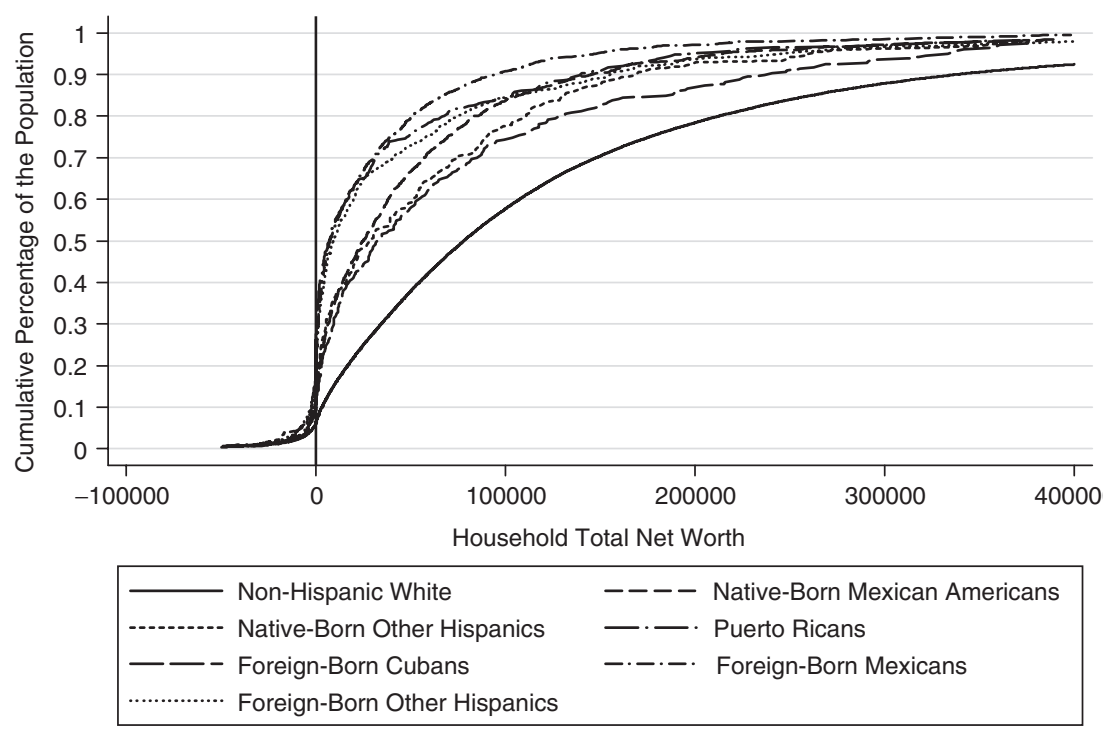

cumulative effect of income disparities over a number of years or perhaps decades. Still, given the link between wealth and economic well-being, these sizeable disparities in net worth underscore the importance of understanding the process through which families do or do not accumulate wealth.

\section{Empirical Specification and the Results}

Our interest is in understanding the extent to which differences in the demographic characteristics and income levels of various groups affect portfolio decisions and the subsequent asset holdings of Hispanic couples. We will begin by explicitly considering the factors determining overall wealth levels and then move on to estimate the determinants of asset portfolios conditional on net worth.

\section{Net Worth}

Understanding how wealth levels vary with household characteristics requires estimating the determinants of net worth. Our conceptual framework is based upon a life-cycle model in which wealth disparities arise from differences in inherited wealth, rates of return, or in previous income and consumption patterns that together determine savings behavior. This 
conceptual framework informs the choices of variables to be included in our reduced-form model. As the distribution of wealth is quite skewed, researchers often use a log-transformation of wealth in order to obtain a lognormally distributed dependent variable. This transformation is problematic for households with negative or zero net worth, however, so we adopt an inverse hyperbolic sine transformation-denoted as $\sinh ^{-1}$ - that is defined for households with nonpositive net worth. ${ }^{16}$ Specifically, we estimate a reduced-form model of net worth $\left(W_{i t}\right)$ for household $i$ at time $t$ as follows:

$$
\begin{aligned}
\sinh ^{-1}\left(W_{i t}\right)= & \alpha_{0}+Y_{i t} \beta+X_{i t} \gamma+L_{i t} \lambda+H_{i}\left(\alpha_{1}+R_{i} \theta+I_{i} C_{i} \pi\right. \\
& \left.+Z_{i t} \kappa\right)+t \delta+\eta_{i t},
\end{aligned}
$$

where $Y_{i t}$ is a vector of the household's permanent and transitory income. Life-cycle theory predicts that savings and consumption decisions-and, ultimately, wealth accumulation — are based on a household's permanent (as opposed to current) income. Specifically, households are expected to smooth their consumption over their lifecycle by dis-saving in periods of relatively low current income and saving in periods of relatively high current income. At the same time, income uncertainty or credit constraints imply that consumption smoothing is often difficult, leading income shocks to perhaps have an independent effect on savings and consumption behavior. Consequently, we incorporate both permanent and transitory income into our wealth model. We generate a measure of permanent income by estimating an income regression separately by Hispanic-origin group and predicting income for each couple in our sample. Transitory income is measured as the difference between permanent and current income so that positive values reflect a lower than expected current income. ${ }^{17}$ Further, $X_{i t}$ is a vector of demographic variables that capture a household's stage of the lifecycle and as such are allowed to have a direct effect on a family's wealth position. ${ }^{18}$ Other characteristics, for example, education and occupation, affect net worth and asset portfolios only indirectly through their effect on permanent income. Geographic disparities in housing markets are accounted for by the inclusion of controls for region of residence, $L_{i t}$, while $t$ is a vector of time period dummies.

\footnotetext{
${ }^{16}$ This function approximates $\log \left(W_{i t}\right)$ for positive values of net worth that are not too small and $-\log \left(W_{i t}\right)$ for negative values of net worth that are small enough. See Burbidge, Magee, and Robb (1988) and Cobb-Clark and Hildebrand (2006a).

${ }^{19}$ The explanatory variables in the income regression include: a cubic in age of the head, education (for both head and spouse), head's occupation (including a dummy for not employed), Census region, time period dummies, and Hispanic-origin group dummies. This income regression is estimated using data pooled across SIPP panels. See Cobb-Clark and Hildebrand (2006a) for a discussion of the difficulties in measuring permanent income in the SIPP data and the alternative methods that have been adopted in the wealth literature. An inverse hyperbolic sine transformation has been used for both permanent and transitory income.

${ }^{18}$ The variables in $X_{i t}$ include: a cubic in age of the head, the number of children aged less than 18 in the household, years of marriage, and dummies for the previous marriages of the partners.
} 
In Equation (1), $H_{i}$ is a dummy variable that equals 1 for Hispanic couples and 0 otherwise, $I_{i}$ is a dummy variable indicating foreign-born status, and $R_{i}$ and $C_{i}$ are complete sets of Hispanic-origin group and year-ofarrival cohort dummy variables, respectively. To allow for the possibility that the effect of transitory income shocks on wealth differs for Hispanics, we also include interactions $\left(Z_{i t}\right)$ of transitory income with Hispanic status $\left(H_{i}\right)$ and Hispanic-origin group $\left(R_{i}\right)$. Equation $(1)$ is identified by constraining the coefficients on the region of residence, Hispanic-origin, cohort, and period dummies, as well as the transitory-income interactions to sum to zero. ${ }^{19}$ Finally, $\eta_{i t} \sim N\left(0, \sigma^{2}\right)$ is a random error term and the remaining terms are vectors of parameters to be estimated.

The results-marginal effects and $t$ statistics-from this estimation are presented in Table $2 .^{20}$ Two specifications of the model are considered: our baseline specification and one that includes the transitory income interactions.

Income and demographic characteristics are closely related to wealth levels. Every dollar increase in permanent income is estimated to result in an additional $\$ 23.33$ in net worth. At the same time, couples have approximately $\$ 14$ less net worth for every dollar their current income falls below their permanent income. Older couples and those who have been married for longer have more wealth, while previous marriages and children are associated with less wealth.

The wealth gap for Hispanic couples as a whole is approximately $\$ 70,000$, which amounts to 77 percent of the unconditional wealth gap reported in Table 1. There are large differentials across Hispanic-origin groups, however. Mexican-American couples have significantly more wealth than Hispanics as a whole once their characteristics are taken into account-though they still face a wealth gap relative to whites. This is consistent with previous research suggesting that Mexican Americans' wealth disadvantage stems mainly from their income, education levels, demographic characteristics, and so forth and not from the way they accumulate wealth conditional on their characteristics (Cobb-Clark and Hildebrand, 2006b). In contrast, Puerto Rican couples have significantly less wealth than other Hispanic couples. For them, the wealth gap relative to whites is estimated to be almost $\$ 160,000$. $^{21}$ It is difficult to know whether this enormous gap reflects the savings and consumption behavior of Puerto Ricans or whether their unique

\footnotetext{
${ }^{19}$ This identification strategy facilitates the interpretation of the results. Specifically, $\alpha_{0}$ captures the net worth of non-Hispanic white couples across all years, while $\alpha_{1}$ is a measure of the extent to which the net worth of Hispanic couples (across all groups) differs from that of whites.

${ }^{20}$ Coefficients estimated from the above model have been converted into marginal effects, which show the change in net worth (measured in dollars) for each one-unit change in the underlying independent variable (see Cobb-Clark and Hildebrand, 2006a). Bootstrapped standard errors for these marginal effects were used to calculate the reported $t$ statistics.

${ }^{21}$ This can be seen by considering both the Hispanic-status and Hispanic-group effects. Given the nonlinear nature of the marginal effects resulting from the inverse hyperbolic sine transformation, it is not possible to simply add these effects to get the total effect as it would be in the linear case. Adding these effects does provide a reasonable approximation, however.
} 
TABLE 2

Determinants of Net Worth by Household Type (Marginal Effects and $t$ Statistics)

\begin{tabular}{|c|c|c|c|c|}
\hline & $d y / d x$ & $t$ stat & $d y / d x$ & $t$ stat \\
\hline Permanent income & 23.33 & 38.49 & 23.33 & 35.59 \\
\hline Transitory income & -14.40 & -36.97 & -14.21 & -34.74 \\
\hline \multicolumn{5}{|l|}{ Demographics } \\
\hline Age & 14074.98 & 32.38 & 14078.87 & 33.37 \\
\hline Kids $<18$ & 1272.82 & 0.36 & 1314.13 & 0.37 \\
\hline Yrs. married & 2272.40 & 5.84 & 2260.92 & 5.51 \\
\hline Head prev. married & -95576.10 & -11.45 & -95587.30 & -10.57 \\
\hline Spouse prev. married & -33212.70 & -3.74 & -33313.80 & -3.96 \\
\hline \multicolumn{5}{|l|}{ Region of Residence } \\
\hline Northeast & 23589.58 & 4.78 & 23660.04 & 4.63 \\
\hline Midwest & 11540.86 & 2.65 & 11532.09 & 2.73 \\
\hline South & -7141.18 & -1.65 & -6839.40 & -1.50 \\
\hline West & -27989.30 & -5.02 & -28352.70 & -4.95 \\
\hline \multicolumn{5}{|l|}{ Hispanics } \\
\hline Hispanic & -68566.80 & -10.94 & -70104.40 & -10.01 \\
\hline \multicolumn{5}{|l|}{ Hispanic Group } \\
\hline NBMAs & 46079.93 & 5.54 & 43646.88 & 4.69 \\
\hline $\mathrm{NBOHs}$ & 22122.56 & 1.36 & 22875.58 & 1.39 \\
\hline Puerto Ricans & -85462.90 & -5.20 & -89061.90 & -4.94 \\
\hline FBCUs & 2454.00 & 0.13 & 4762.47 & 0.27 \\
\hline FBMAs & 45682.87 & 4.95 & 46857.63 & 5.30 \\
\hline $\mathrm{FBOHs}$ & -30876.50 & -2.49 & -29080.60 & -2.10 \\
\hline \multicolumn{5}{|l|}{ Year of Entry } \\
\hline$<1965$ & 19340.12 & 1.79 & 19442.61 & 1.76 \\
\hline 1965-1974 & 12532.75 & 1.32 & 12469.21 & 1.24 \\
\hline 1975-1984 & -7364.62 & -0.74 & -7346.47 & -0.78 \\
\hline $1985+$ & -24508.20 & -2.63 & -24565.4 & -2.32 \\
\hline \multicolumn{5}{|l|}{ Transitory Income } \\
\hline \multicolumn{5}{|l|}{ Interactions } \\
\hline$\times$ Hispanic & & & -1.55 & -1.07 \\
\hline$\times$ NBMAs & & & -2.02 & -0.87 \\
\hline$\times \mathrm{NBOHs}$ & & & 0.45 & 0.28 \\
\hline$\times$ Puerto Ricans & & & -2.81 & -0.50 \\
\hline$\times$ FBCUs & & & 2.46 & 0.62 \\
\hline$\times$ FBMAs & & & 1.18 & 0.61 \\
\hline$\times \mathrm{FBOHs}$ & & & 0.74 & 0.63 \\
\hline Panel Years Included & Yes & & Yes & \\
\hline$N$ & 64,343 & & 64,343 & \\
\hline$R^{2}$ & 0.15 & & 0.15 & \\
\hline
\end{tabular}

Note: $N B M A s=$ Native-born Mexican Americans, NBOHs $=$ Native-born other Hispanics, FBCUs $=$ Foreign-born Cubans, FBMAs $=$ Foreign-born Mexican Americans, FBOHs $=$ Foreign-born other Hispanics.

entitlement to U.S. citizenship causes them to hold relatively more assets offshore. These disparities are perhaps not surprising in light of the differences in the earnings and expenditure patterns of different groups. Still, 
the results do highlight the importance of considering the wealth position of different Hispanic-origin groups separately. ${ }^{22}$

Finally, there is no evidence that transitory income shocks have a differential effect on the wealth accumulation of white and Hispanic coupleseither in total or across Hispanic-origin groups. Thus, we find little support for the notion that credit constraints or limited access to financial markets lead Hispanics experiencing transitory income shocks to differentially maintain current consumption levels by reducing wealth levels.

\section{Asset Portfolios}

In addition to having different wealth levels, it is also the case that Hispanics allocate their wealth differently across asset types (see Table 1). One possibility is that these differences in portfolio choices reflect ethnic differences in factors such as income or life-cycle stage that impact on the way families allocate their wealth. Alternatively, these differences may arise from disparities in wealth levels themselves. To investigate these issues, it is useful to compare the asset portfolios of couples who are equally wealthy. Consequently, we estimate the following reduced-form model of asset composition:

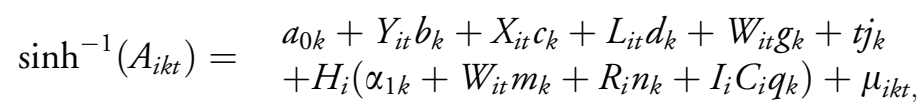

where $A_{i k t}$ is the dollar value of asset $k$ that household $i$ holds in time period $t$. We consider four major asset categories including financial wealth and equity in businesses, real estate, and vehicles (see above). Following Blau and Graham (1990), we allow asset composition to depend on net worth $\left(W_{i t}\right)$ in order to account for any capital market imperfections (such as credit constraints) that might vary across families and be related to the choice to hold a particular asset. Differences in the effect of wealth in the asset portfolios of Hispanic couples (relative to whites) are captured in Equation (2) by an interaction term between net worth $\left(W_{i t}\right)$ and Hispanic status $\left(H_{i}\right)$. As before, $Y_{i t}, X_{i t}, L_{i t}$, and $t$ capture income (both permanent and transitory), demographic characteristics, region of residence, and time period effects, respectively (see previous section), while the asset portfolios of Hispanic couples are allowed to differ across regions of origin $\left(R_{i}\right)$ and-for immigrants $\left(I_{i}\right)$ - entry cohorts $\left(C_{i}\right)$. The other variables are parameters to be estimated. Finally, Equation (2) is estimated as a system of equations and

\footnotetext{
${ }^{22}$ We tested the robustness of our conclusions regarding Hispanic-origin groups to the inclusion of "mixed" Hispanic/white households (see above) by dropping them from the sample and reestimating the model. We also investigated the sensitivity of our results to excluding couples in which partners - while both Hispanic - differed in either nativity status or region of origin. In both cases, the results were substantially unchanged and are available on request.
} 
cross-equation restrictions are imposed in order to satisfy the adding-up requirement that the sum of assets across asset types equals net worth. ${ }^{23}$

Marginal effects and $t$ statistics from this estimation are presented in Table $3 .^{24}$ The estimated distribution of an additional dollar of net wealth across asset types is given by the marginal effect on net worth. Other marginal effects show the effect of a one-unit change in the corresponding independent variable on a specific asset-holding wealth levels constant. This implies that the sum of the marginal effects of any specific independent variable must sum to zero across the four asset types.

These results suggest that the way couples hold their wealth is strongly related to income levels, household composition, and marital history. For every dollar increase in permanent income-holding net worth constantcouples hold $\$ 2.48$ less in real estate and $\$ 1.63$ more in financial wealth. In contrast, lower than expected current income, that is, a transitory income shock, is associated with holding less financial wealth and more real estate. Couples with children under the age of 18 allocate relatively more of their wealth to real estate and business assets, and relatively less to financial assets and vehicles than do equally wealthy childless couples. Moreover, financial wealth is lower and real estate equity higher among couples who have been together longer, while previous marriages are associated with holding less financial wealth and more real estate equity.

Hispanic couples on average have significantly less financial wealth $(\$ 11,364)$ and vehicle equity $(\$ 9,335)$, but significantly more real estate $(\$ 18,035)$ and business $(\$ 2,664)$ assets than equally wealthy white couples. This ethnic gap in financial wealth is much smaller than the unconditional gap reported in Table 1, implying that much of the disparity in the asset portfolios of Hispanic couples stems from the fact that Hispanics are simply less wealthy. In particular, unconditional estimates confirm previous evidence that Hispanic couples are much less likely to own their own homesand have less equity when they do-than are white couples (see also Choudhury, 2001; Kochhar, 2004; Smith, 1995)). This gap in real estate holdings disappears once we control for the income levels, demographic characteristics, and-perhaps most importantly—net worth of white and Hispanic couples. Thus, when drawing comparisons between the asset holding of different ethnic groups it is important to compare families that are equally wealthy. Controlling for net worth, Hispanic couples are estimated to hold significantly more real estate wealth than white couples with similar characteristics.

\footnotetext{
${ }^{23}$ Specifically, we require that the estimated marginal effect of an additional dollar of wealth sum to 1 across asset types, while the marginal effect of a change in any other independent variable is restricted to sum to 0 . Note that while these constraints hold on average, they may not hold for any particular couple.

${ }^{24}$ Marginal effects and bootstrapped standard errors were calculated in the same manner as above.
} 


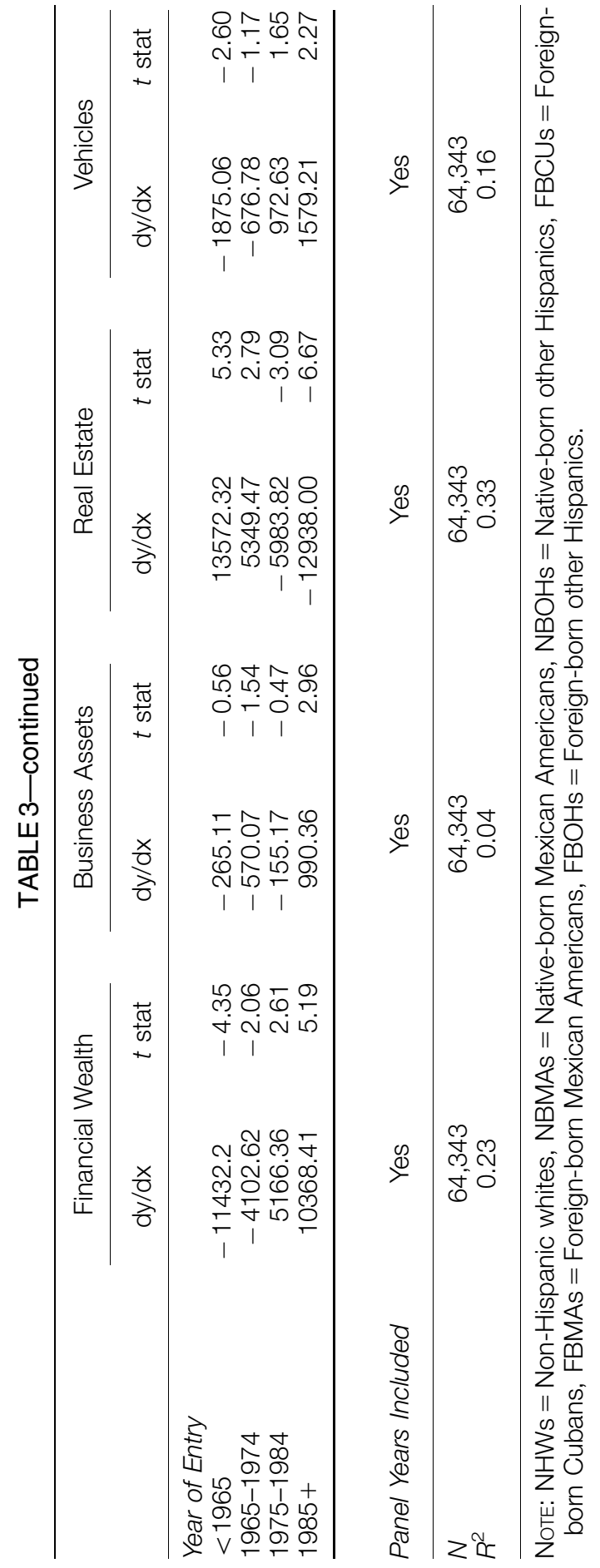


Still, once we control for wealth, we continue to observe that Hispanic couples have less financial wealth than white couples. Moreover, as their wealth grows, Hispanics allocate their wealth across the asset categories in a somewhat different manner than do white couples. For every additional dollar of increased net worth, white couples add $\$ 0.51$ to their financial wealth and $\$ 0.41$ to their real estate holdings, leaving their business and vehicle equity almost unchanged. In contrast, Hispanic couples use an additional dollar of wealth largely to increase vehicle equity $(\$ 0.57)$ and real estate holdings $(\$ 0.26)$. Hispanics allocate just $\$ 0.18$ to financial assets for every dollar of additional wealth they receive. This ethnic gap in financial wealth-while consistent with previous evidence (Choudhury, 2001; Wolff, 1998, 2000)_does imply that many Hispanic couples may find it difficult to generate sufficient levels of asset income in their retirement years.

There is, however, substantial heterogeneity in the asset portfolios of different Hispanic-origin groups. This diversity is primarily the result of nativity rather than source-region effects. Foreign-born Hispanics and Puerto Ricans hold more financial wealth than other Hispanics, although the difference is not always significant. In fact, Puerto Ricans and foreignborn other Hispanics hold levels of financial assets that are similar to white couples who are equally wealthy. Native-born Hispanic couples, on the other hand, allocate substantially more of their wealth to real estate. Overall, native-born Hispanic couples hold approximately $\$ 25,000-35,000$ more in real estate than otherwise similar white couples with the same level of net worth, while the differential for foreign-born Hispanic couples is approximately $\$ 8,000-15,000$. These distinctions between native- and foreignborn Hispanics may arise either because immigrants face credit constraints that make financing assets such as stocks and bonds easier than real estate or because the prospect of remigration gives rise to a preference for liquid rather than nonliquid assets. ${ }^{25}$

\section{Conclusions}

Wealth is an important measure of economic well-being. Wealth provides the resources necessary to maintain consumption in the face of financial difficulties, to provide adequate retirement income, and to achieve a high standard of living. Unfortunately, there is much we do not understand about the wealth position of Hispanics. Although it is clear that Hispanic families are less wealthy than their white counterparts, we know less about how relative wealth varies across Hispanic-origin groups. Nor is it clear what lies behind the portfolio choices of Hispanics or what role portfolio choices might play in producing these wealth gaps.

${ }^{25}$ Cobb-Clark and Hildebrand (2006a) discuss similar results for immigrants as a whole. 
This article adds to the limited empirical literature on Hispanic wealth by using SIPP data to document how the wealth levels and portfolio choices of Hispanic couples compare to those of white couples with similar characteristics and income levels. Our results indicate that-as expected-Hispanic couples are less wealthy than their white counterparts. Hispanic couples hold on average approximately $\$ 91,000$ less in net worth than white couples (see Table 1). Controlling for income and demographic characteristics reduces this gap somewhat, although the vast majority of the wealth gap-approximately $\$ 70,000$ - remains even after these factors are taken into account (see Table 2). Thus, it is not the case that the wealth gap is easily explained by differences in income streams or life-cycle stages that might lead Hispanics to accumulate wealth at a different rate.

There are large disparities across Hispanic-origin groups, however, with Mexican-American couples and native-born other Hispanics holding significantly more wealth and Puerto Ricans holding significantly less U.S. wealth than Hispanics as a whole. More detailed surveys would be useful in understanding the extent to which these patterns arise from a differential propensity to hold wealth offshore. Although off-shore wealth is not explicitly excluded from wealth surveys such as SIPP it is generally not directly included either, raising questions about how wealth held abroad may be impacting on measured wealth levels. In any event, our results point to the importance of separately analyzing the wealth position of distinct Hispanicorigin groups. Unfortunately, standard data collections do not always provide the necessary detail about nativity status, year of arrival, ethnic background, and so forth for researchers to make these distinctions.

Portfolio choices also depend on Hispanic status even after controlling for wealth, income, and demographic characteristics. Unlike the case for net worth, these disparities in portfolio allocations are much smaller than-and in the case of real estate, opposite to-the unconditional gaps. This suggests that much of the disparity in the portfolio choices of Hispanic couples stems from the fact that Hispanics have less wealth. Thus, it is important to estimate the determinants of the ownership of individual assets (such as real estate) in the context of a model that can account for overall wealth levels and the full range of assets over which individuals are allocating their wealth. Analyses that study individual assets in isolation may generate misleading results.

At the same time, even accounting for aggregate wealth levels, Hispanics as a group hold relatively less financial wealth and more real estate. Moreover, Hispanics appear to be disinclined to increase their financial wealth, allocating just $\$ 0.18$ (as opposed to $\$ 0.51$ for white couples) for every dollar of additional wealth they acquire. This finding confirms previous research raising questions about the ability of Hispanics to generate sufficient asset income in retirement (see Smith, 1995). Additional research assessing the reasons for Hispanics' apparent reluctance to hold financial wealth would be useful in understanding the financial vulnerability of Hispanic families. 
Policymakers would benefit from knowing whether this gap in financial wealth stems from cultural factors related to portfolio decisions along the lines suggested by Chiteji and Stafford (1999) and Osili and Paulson (2005), or from financial market imperfections related to discrimination, credit constraints, information asymmetries, and the like.

Finally, the results also highlight the importance of nativity status in understanding the wealth position of Hispanics. Native-born Hispanics hold more of their wealth in real estate while foreign-born Hispanics hold relatively more financial wealth. Whether this occurs because of credit constraints that make it relatively difficult for immigrants to finance real estate, or whether the prospect of remigration heightens preferences for liquid as opposed to nonliquid assets, is an important question for future research.

\section{REFERENCES}

Altonji, J. G., and U. Doraszelski. 2005. "The Role of Permanent Income and Demographics in Black/White Differences in Wealth." Journal of Human Resources 40(1):1-30.

Amuedo-Dorantes, C., and S. Pozo. 2002. "Precautionary Savings by Young Immigrants and Young Natives." Southern Economic Journal 69(1):48-71.

Bertaut, C., and M. Starr-McCluer. 1999. Household Portfolios in the United States. FEDS Working Paper No. 2000-26. Federal Reserve Board of Governors.

Blau, F. D., and J. W. Graham. 1990. "Black-White Differences in Wealth and Asset Composition." Quarterly Journal of Economics 105(2):321-39.

Burbidge, J., L. Magee, and A. Robb. 1988. "Alternative Transformations to Handle Extreme Values of the Dependent Variable." Journal of the American Statistical Association 83(401):123-27.

Chiteji, N. S., and F. P. Stafford. 1999. "Portfolio Choices of Parents and Their Children as Young Adults: Asset Accumulation by African-American Families." American Economic Review 89(2):377-80.

Choudhury, S. 2001. "Racial and Ethnic Differences in Wealth and Asset Choices." Social Security Bulletin 64(4):10-15.

Cobb-Clark, Deborah A., and Vincent A. Hildebrand. 2006a. "The Wealth and Asset Holdings of U.S.-Born and Foreign-Born Households: Evidence from SIPP Data." Review of Income and Wealth 52(1):17-42.

2006b. "The Wealth of Mexican Americans." Journal of Human Resources 41(4).

Gittleman, M., and E. N. Wolff. 2000. "Racial Differences in Patterns of Wealth Accumulation.” Journal of Human Resources 39(1):193-227.

Grogger, J., and S. J. Trejo. 2002. Falling Behind or Moving Up? The Intergenerational Progress of Mexican Americans. Technical Report. San Francisco, CA: Public Policy Institute of California.

Hao, L. 2003. Immigration and Wealth Inequality in the U.S. Working Paper 202. Russell Sage Foundation. 
Haurin, Donald, R., Robert D. Dietz, and B. Weinberg. 2002. "The Impact of Neighborhood Homeownership Rates: A Review of the Theoretical and Empirical Literature." Journal of Housing Research 13(2):119-51.

Hurst, E., C. L. Ming, and F. Stafford. 1998. "The Wealth Dynamics of American Families, 1984-94." Brookings Papers on Economic Activity 1:267-337.

Kochhar, R. 2004. The Wealth of Hispanic Households: 1996-2002. Washington, DC: Pew Hispanic Center.

Menchik, P. L., and N. A. Jianakoplos. 1997. "Black-White Wealth Inequality: Is Inheritance the Reason?” Economic Inquiry XXXV:428-42.

Osili, U. O., and A. Paulson. 2004. Prospects for Immigrant-Native Wealth Assimilation: Evidence from Financial Market Participation. Working Paper 04-18. Chicago, IL: Federal Reserve Bank of Chicago.

2005. Institutional Quality and Financial Market Development: Evidence from International Migrants in the U.S. Working Paper 04-19. Chicago, IL: Federal Reserve Bank of Chicago.

Paulin, G. D. 2003. "A Changing Market: Expenditures by Hispanic Consumers, Revisited." Monthly Labor Review 126(8):12-35.

Smith, J. P. 1995. "Racial and Ethnic Differentials in Wealth in the HRS." Journal of Human Resources 30:S158-83.

1995. Economics and Statistics Administration. The Nation's Hispanic Population1994. Statistical Brief SB/95-25. Washington, DC: U.S. Government Printing Office.

2001a. Economics and Statistics Administration. The Hispanic Population: Census 2000 Brief. Current Population Reports P20-535. Washington, DC: U.S. Government Printing Office.

U.S. Bureau of the Census. 2001b. Economics and Statistics Administration. The Hispanic Population in the United States: Census 2000 Brief. Current Population Reports P20-535. Washington, DC: U.S. Government Printing Office.

Wakita, S., V. S. Fitzsimmons, and T. F. Liao. 2000. "Wealth: Determinants of Savings Net Worth and Housing Net Worth of Pre-Retired Households." Journal of Family and Economic Issues 21(4):387-418.

Wolff, E. N. 1998. "Recent Trends in the Size Distribution of Household Wealth." Journal of Economic Perspectives 12(3):131-50.

2000. "Recent Trends in Wealth Ownership, 1983-1998." Pp. 24-73 in T.

Shapiro and E. Wolff, eds., Assets for the Poor. New York: Russell Sage Foundation. 
